\title{
Characterisation of urinary isolates of Escherichia coli by multiple typing: a retrospective analysis
}

\author{
MARGARET I WILSON, PAMELA B CRICHTON, AND DC OLD \\ From the Bacteriology Department, University of Dundee Medical School, Ninewells Hospital, \\ Dundee DDI $9 S Y$, UK
}

SUMMARY Cultures of Escherichia coli of urinary origin were examined after storage for 12 to $15 \stackrel{\dot{\omega}_{\perp}}{\dot{\omega}}$ years by a combination of the techniques of biotyping, resistotyping, haemagglutinin typing, and colicin typing (multiple typing) which allowed strain identification to be made even when variation in $\underset{\oplus}{\mathbb{N}}$ one or more typing characters had occurred in vivo. Biotyping and resistotyping used in conjunction $\mathrm{s}$ were sufficient to allow identification of as many as 106 of 110 pairs of $E$. coli examined. In the four pairs of isolates for which it was necessary to extend strain identification profiles to include data from $\rightarrow$ other typing methods, probable strain identification was achieved for all but one pair. The multiple typing approach seems useful for retrospective analysis of stored cultures of $E$. coli.

In patients with recurrent urinary tract infection, it is important to differentiate between relapse, as a result of failure to eradicate the original causative organism, and reinfection by a strain different from that previously implicated. For Escherichia coli, the commonest urinary pathogen, serotyping has been the principal means of strain differentiation, but few laboratories have the resources to prepare the many antisera required for either complete $(\mathrm{O}, \mathrm{H}$, and $\mathrm{K})$ or, indeed, even restricted $(\mathrm{O})$ antigen characterisation.

Thus other reliable and discriminatory methods of typing $E$. coli, such as resistotyping ${ }^{1}$ and biotyping, ${ }^{2}$ are invaluable in smaller laboratories. However, members of a common serogroup, or biotype or resistotype, may be unrelated, and we have therefore preferred to use several typing methods in conjunction (multiple typing) for the accurate characterisation of fresh isolates of $E$. coli. ${ }^{34}$

One of us had available a collection of cultures of $E$. coli of urinary origin, many of which had not been serotypable when originally examined ${ }^{5}$ and all of which had been stored on non-selective medium for 12 to 15 years. We assess the efficiency of discrimination of these strains achieved by the use of multiple typing and consider its usefulness for retrospective analysis.

Accepted for publication 24 September 1980

\section{Material and methods}

PATIENTS AND STRAINS

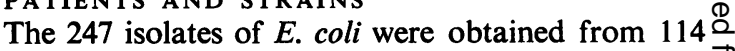
patients -35 children under 12 years of age and $\overrightarrow{\overrightarrow{0}}$ 79 adults ( 7 men and 72 women) aged 20 to 923 years-with significant bacteriuria, that is, $>10^{8}$ 卉 bacteria per litre of freshly voided urine. The isolates had been stored at ambient temperature on Dorset's egg medium since 1965-8. Multiple isolates from four $\overline{-}$ patients (Table 1) will be used to demonstrate 3 . particular aspects of multiple typing. Paired isolates were available from another 110 patients; the time intervals in days between isolation of the members of 0 the pairs were: 0 , that is, the same day ( 7 pairs), 1-100 days (74), 101-300 days (22), and 301-570 days (7).

\section{TYPING METHODS}

O serogroups were determined, as previously, ${ }^{2}$ with commercial sera (Wellcome Reagents Ldt, Becken- $\frac{\omega}{\sigma}$ ham, Kent): 01, 02, O4, O5, O6, 09, 011, 018, O39, and 075 (urinary types); O26, O44, O55, O86, O111, 0112, 0114, 0119, 0124, O125, O126, O127, 0128, and 0142 (enteropathogenic types).

The 10 biotyping tests were: fermentation of $\frac{0}{0}$ dulcitol (dul), raffinose (raf), rhamnose (rha), sorbose $\frac{\vec{\Phi}}{\Phi}$ (sor), and sucrose (suc), decarboxylation of lysine $\frac{\stackrel{\rho}{\Phi}}{2}$ (lys) and ornithine (orn), hydrolysis of aesculin (aes), motility (mot), and prototrophy (pro). Details of 
tests and their interpretation have been given ${ }^{2}$ except for a modification in the sucrose fermentation test. Sucrose $(1 \%)$ EMB agar, ${ }^{6}$ inoculated with $c 10^{7}$ bacteria, was incubated at $37^{\circ} \mathrm{C}$ for 24 hours; the growth of strong (s), weak (w), and non (n) fermenters was, respectively, black with green metallic sheen, purple-pink, and colourless. Full biotype profiles are given (Tables 1 and 3) for only a few chosen strains.

The chemicals used in resistotyping ${ }^{1}$ were: A, sodium arsenate; $B$, phenylmercuric nitrate; C, 4:4'diamidinodiphenylamine dihydrochloride; $D$, boric acid; E, acriflavine; F, 4-chloresorcinol; G, copper sulphate; and $H$, malachite green. The selective toxicity of the chemicals has such fine margins that a biological titration of each chemical was performed each time strains were resistotyped. For each chemical, a narrow range of concentrations around its optimal concentration ${ }^{134}$ was tested. Thus, 20 test strains and five reference strains ${ }^{134}$ were inoculated to every plate in each series that contained varying concentrations of each of the eight chemicals. In this way, the biological titration of the chemicals by the use of the reference strains was performed at the same time as the test strains were typed and ensured the optimal differentiation of each strain with regard to each chemical. The effect of the chemicals on the growth of the strains was assessed, and strains were classed as resistant, partially resistant, or sensitive. ${ }^{1}$ We have modified our reporting of resistotype profiles: thus, pattern $\mathrm{CDeFh}$ indicates a strain resistant to chemicals $\mathrm{C}, \mathrm{D}$, and $\mathrm{F}$, partially resistant to $E$ and $H$, and sensitive to $A, B$, and $G$. Isolates different in one partial resistance, for example, $\mathrm{CDeFH}$ and $\mathrm{CDeFh}$, were considered identical. ${ }^{1}$
We examined strains for their ability to form (i) mannose-sensitive (MS) haemagglutinin (HA), and (ii) mannose-resistant and eluting (MRE) HA by cultural methods and tests previously described.? The latter MRE HA were characterised by their agglutination of some, or all, of the erythrocyte species: fowl $(F)$, guinea-pig $(G)$, horse $(H)$, man group O (M), ox (O), pig (P), and sheep (S). The HA type of a strain that produced, for example, MS HA and an MRE HA reacting with erythrocytes of man, pig, and sheep was $\mathrm{MS}^{+} \mathrm{MRE}^{+}$(type MPS).

Cultures were examined for colicin production by an agar overlay method, ${ }^{8}$ and colicins were identified with the use of standard indicator strains. ${ }^{9}$ Sensitivity to known colicins was also assessed.

\section{Results}

\section{GENERAL COMMENTS}

Some interesting points emerged from examination of the multiple typing results for serologically untypable strains of E. coli from patients 1 to 4 (Table 1): (i) although the first isolate of the four from patient 1 showed partial resistance to acriflavine (e), it was otherwise identical with the other three cultures, and the four were considered to be isolates of the same clone; (ii) the combined techniques identified the presence of five distinct strains in a series of six isolated from patient 2 over a one-year period, the first and last being the only members that were, respectively, $\mathrm{MRE}^{+}$and $\mathrm{MS}^{-}$; (iii) the reproducibility of the systems allowed the detection of relapse of infection with the original strain in patient 3 over a period of 227 days and reinfection in the intervening period (days 10-14) with a second strain clearly different by all three methods; (iv) although minor

Table 1 Typing results for 27 urinary isolates of E. coli from four patients

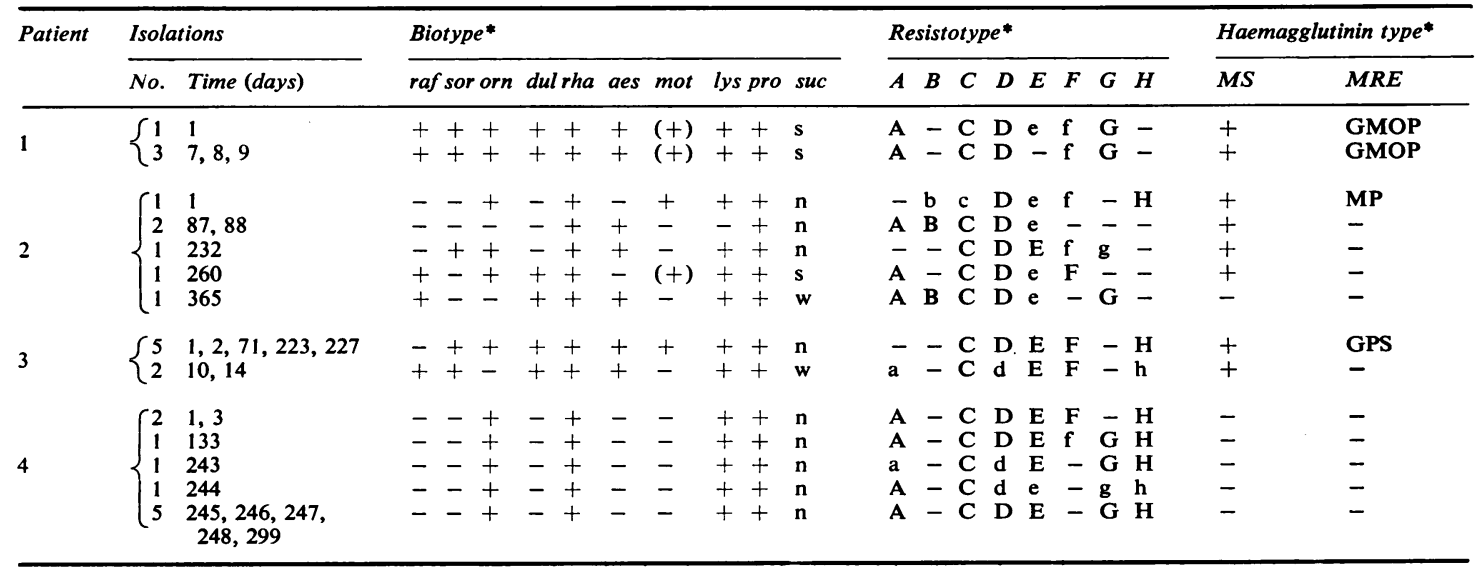


Table 2 Typing of 110 pairs of urinary isolates of $\mathrm{E}$. coli from 110 patients

\begin{tabular}{|c|c|c|c|c|}
\hline \multirow{2}{*}{$\begin{array}{l}\text { Method of } \\
\text { typing }\end{array}$} & \multicolumn{4}{|c|}{ No. of pairs classified by the stated method of typing as: } \\
\hline & Similar & Different & Of uncertain status & Untypable \\
\hline $\begin{array}{l}\text { O Serogrouping } \\
\text { Biotyping } \\
\text { Resistotyping } \\
\text { Biotyping and resistotyping }\end{array}$ & $\begin{array}{l}36 * \\
75 \dagger \\
76 \ddagger \\
73\end{array}$ & $\begin{array}{l}3 \\
35 \S \\
34 \| \\
33\end{array}$ & $\begin{array}{l}0 \\
0 \\
0 \\
4\end{array}$ & $\begin{array}{r}71 \\
0 \\
0 \\
0\end{array}$ \\
\hline
\end{tabular}

Subsequent testing by the other methods (see Table 3) showed that:

*Two of the 36 pairs (patients 5 and 6 ) were different;

tOne of the 75 pairs (patient 7 ) was different;

†One of the 76 pairs (patient 8) was different;

§One of the 35 pairs (patient 11) was similar, another (patient 12) was of uncertain status;

$\|$ Two of the 34 pairs (patients 9 and 10) were similar.

Table 3 Discrimination of pairs of strains of $\mathrm{E}$. coli achieved by multiple typing

\begin{tabular}{|c|c|c|c|c|c|c|c|c|c|c|c|c|c|c|c|c|c|c|}
\hline \multirow[t]{2}{*}{ Patient } & \multirow{2}{*}{$\begin{array}{l}\text { First and } \\
\text { subsequent } \\
\text { isolates (days) }\end{array}$} & \multicolumn{6}{|l|}{ Biotype } & \multicolumn{8}{|c|}{ Resistotype } & \multicolumn{2}{|c|}{ Haemagglutinin type } & \multirow{2}{*}{$\begin{array}{l}O^{*} \\
\text { sero- } \\
\text { group }\end{array}$} \\
\hline & & raf sor orn & dul rha & aes & mot & lys pro & suc & $A$ & $\boldsymbol{B}$ & $C$ & $D$ & $E$ & $F$ & $G$ & $H$ & $M S$ & $M R E$ & \\
\hline 5 & $\left\{\begin{array}{r}1 \\
53\end{array}\right.$ & $\begin{array}{l}-++ \\
+-+\end{array}$ & $\begin{array}{l}++ \\
++\end{array}$ & $\stackrel{+}{-}$ & $\begin{array}{l}+ \\
+\end{array}$ & $\begin{array}{l}++ \\
++\end{array}$ & $\begin{array}{l}\mathrm{n} \\
\mathrm{s}\end{array}$ & - & $\overline{\mathbf{B}}$ & $\begin{array}{l}\text { C } \\
\text { C }\end{array}$ & $\begin{array}{l}\text { D } \\
\text { D }\end{array}$ & $\begin{array}{l}\mathbf{E} \\
\mathbf{E}\end{array}$ & $\begin{array}{l}F \\
F\end{array}$ & $\begin{array}{l}-h \\
-h\end{array}$ & $\begin{array}{l}\mathrm{h} \\
\mathrm{h}\end{array}$ & + & OS & $\begin{array}{l}75 \\
75\end{array}$ \\
\hline 6 & $\left\{\begin{array}{r}1 \\
143\end{array}\right.$ & $\begin{array}{l}+++ \\
+++\end{array}$ & $\begin{array}{l}-+ \\
++\end{array}$ & $\begin{array}{l}+ \\
+\end{array}$ & $\overline{+}$ & $\begin{array}{l}++ \\
++\end{array}$ & $\begin{array}{l}\text { s } \\
\text { s }\end{array}$ & - & $\overline{\mathbf{B}}$ & $\begin{array}{l}\mathrm{C} \\
\mathrm{C}\end{array}$ & $\begin{array}{l}\text { D } \\
\text { D }\end{array}$ & $\begin{array}{l}\mathbf{E} \\
\mathbf{E}\end{array}$ & $\begin{array}{l}\mathbf{F} \\
\mathbf{F}\end{array}$ & $\begin{array}{l}-1 \\
-\end{array}$ & h & + & $\begin{array}{l}\text { MPS } \\
\text { M }\end{array}$ & $\begin{array}{l}75 \\
75\end{array}$ \\
\hline 7 & $\left\{\begin{array}{r}1 \\
14\end{array}\right.$ & $\begin{array}{l}-\quad+ \\
--+\end{array}$ & $\begin{array}{l}- \\
-\end{array}$ & $\overline{-}$ & - & $\begin{array}{l}++ \\
++\end{array}$ & $\begin{array}{l}\mathrm{n} \\
\mathrm{n}\end{array}$ & $\bar{a}$ & - & $\begin{array}{l}\mathrm{c} \\
\mathrm{C}\end{array}$ & $\begin{array}{l}\text { D } \\
\text { D }\end{array}$ & $\begin{array}{l}\mathbf{E} \\
\mathbf{E}\end{array}$ & $\begin{array}{l}\mathbf{F} \\
-\end{array}$ & $\begin{array}{l}-1 \\
-\end{array}$ & $\begin{array}{l}\mathbf{H} \\
-\end{array}$ & \pm & - & $\begin{array}{l}\text { NT } \\
\text { NT }\end{array}$ \\
\hline 8 & $\left\{\begin{array}{r}1 \\
358\end{array}\right.$ & $\begin{array}{l}\overline{-}-\overline{+} \\
+\overline{+}\end{array}$ & $\begin{array}{l}+- \\
++\end{array}$ & $\begin{array}{l}+ \\
+\end{array}$ & $\begin{array}{l}+ \\
-\end{array}$ & $\begin{array}{l}++ \\
++\end{array}$ & $\begin{array}{l}\mathrm{n} \\
\mathrm{w}\end{array}$ & $\begin{array}{l}\mathrm{a} \\
\mathrm{a}\end{array}$ & $\begin{array}{l}\text { B } \\
\text { B }\end{array}$ & $\begin{array}{l}\mathrm{C} \\
\mathrm{C}\end{array}$ & $\begin{array}{l}\text { D } \\
\text { D }\end{array}$ & $\begin{array}{l}\mathbf{E} \\
\mathbf{E}\end{array}$ & - & - & - & $\overline{+}$ & OS & $\begin{array}{l}\text { NT } \\
\text { AA }\end{array}$ \\
\hline 9 & $\left\{\begin{array}{r}1 \\
120\end{array}\right.$ & $\begin{array}{l}+-+ \\
+-+\end{array}$ & $\begin{array}{l}-+ \\
-+\end{array}$ & - & - & $\begin{array}{l}++ \\
+-\end{array}$ & $\begin{array}{l}\text { s } \\
\text { s }\end{array}$ & $\overline{-}$ & $\bar{b}$ & $\begin{array}{l}\text { C } \\
\text { c }\end{array}$ & $\begin{array}{l}\mathrm{D} \\
\mathrm{d}\end{array}$ & $\begin{array}{l}\text { e } \\
\text { e }\end{array}$ & - & $\overline{-}$ & - & $\begin{array}{l}- \\
-\end{array}$ & $\begin{array}{l}\text { MOS } \\
\text { MOS }\end{array}$ & $\begin{array}{l}\text { NT } \\
\text { NT }\end{array}$ \\
\hline 10 & $\left\{\begin{array}{r}1 \\
133\end{array}\right.$ & $\begin{array}{l}+++ \\
+++\end{array}$ & $\begin{array}{l}-+ \\
-+\end{array}$ & - & $\begin{array}{l}(+) \\
+\end{array}$ & $\begin{array}{l}+- \\
+-\end{array}$ & $\begin{array}{l}\mathbf{s} \\
\mathbf{s}\end{array}$ & - & $\overline{\mathbf{B}}$ & $\begin{array}{l}\mathrm{C} \\
\mathrm{C}\end{array}$ & $\frac{d}{-}$ & $\begin{array}{l}\mathrm{e} \\
\mathrm{E}\end{array}$ & $\begin{array}{l}F \\
F\end{array}$ & $\overline{-}$ & - & $\begin{array}{l}+ \\
+\end{array}$ & $\begin{array}{l}\text { MOS } \\
\text { MOS }\end{array}$ & $\begin{array}{l}\text { AA } \\
\text { NT }\end{array}$ \\
\hline 11 & $\left\{\begin{array}{l}1 \\
3\end{array}\right.$ & $\begin{array}{l}++- \\
++-\end{array}$ & $\begin{array}{l}+- \\
+-\end{array}$ & $\overline{-}$ & $\overline{-}$ & $\begin{array}{l}-+ \\
++\end{array}$ & s & a & - & $\begin{array}{l}\text { C } \\
\text { C }\end{array}$ & $\begin{array}{l}\mathbf{D} \\
\mathbf{D}\end{array}$ & $\overline{-}$ & $\begin{array}{l}\mathbf{F} \\
\mathbf{F}\end{array}$ & - & - & $\begin{array}{l}+ \\
+\end{array}$ & $\begin{array}{l}\text { MPS } \\
\text { MPS }\end{array}$ & $\begin{array}{l}\text { NT } \\
\text { NT }\end{array}$ \\
\hline 12 & $\left\{\begin{array}{r}1 \\
12\end{array}\right.$ & $\begin{array}{l}--\overline{-} \\
--+\end{array}$ & $\begin{array}{l}++ \\
++\end{array}$ & $\begin{array}{l}- \\
-\end{array}$ & $\overline{-}$ & $\begin{array}{l}++ \\
+-\end{array}$ & $\begin{array}{l}\mathrm{n} \\
\mathrm{n}\end{array}$ & $\frac{a}{-}$ & $\overline{-}$ & $\begin{array}{l}\mathrm{C} \\
\mathrm{C}\end{array}$ & $\begin{array}{l}\text { D } \\
\text { d }\end{array}$ & $\begin{array}{l}\mathbf{E} \\
\mathbf{E}\end{array}$ & - & $\begin{array}{ll}\text { G } & 1 \\
\text { G } & 1\end{array}$ & $\begin{array}{l}\mathrm{h} \\
\mathbf{H}\end{array}$ & - & $\overline{\text { MPS }}$ & $\begin{array}{l}\mathbf{A A} \\
\mathbf{A A}\end{array}$ \\
\hline
\end{tabular}

*AA = autoagglutinable; $\mathrm{NT}=$ not typable with available sera.

variations in the resistotypes of clonal isolates have been noted ${ }^{3} 4$ we observed for the first time, in patient 4 over a 10-month period, the loss of one major resistotype character $(F)$ and the acquisition of another $(G)$ in 10 isolates which, nevertheless, with their stable biotype and uncommon haemagglutinin type were probably clonal.

\section{TYPING OF THE PAIRED ISOLATES}

Serotyping of the 110 pairs of urinary isolates of $E$. coli showed that 36 pairs were similar and three pairs dissimilar (Table 2); 71 pairs were non-serotypable because either the cultures were rough or belonged to $O$ groups not agglutinated by any serum in our collection.

By contrast, we assigned a biotype profile to each of 220 cultures, and in 75 of the 110 pairs, both cultures of the pair were of identical biotype(Table 2); the pairs of cultures from the other 35 patients showed between one and six biotype differences (see some detailed examples in Table 3). Similarly, we assigned a resistotype profile to each culture. Resistotype patterns indicative of strain identity were given by 76 pairs, and of these 74 pairs had been classed as $\frac{T}{0}$ similar by biotyping. In the other 34 pairs, the resistotypes assigned were so different as to suggest $N$ that the members of the pair were isolates of two $\mathrm{N}$ distinct strains (Table 2), and 32 of the pairs had also $N$ been classed as different by biotyping. Thus, pairs of $\omega$ strains similar in biotype were generally of similar resistotype, and pairs of strains different in biotype $\stackrel{\varrho}{\subset}$ were generally of different resistotype. Furthermore, $\stackrel{\infty}{\infty}$ when the 110 pairs of cultures were examined by ? both biotyping and resistotyping, their bio-resisto- $\frac{7}{7}$ types allowed identification of the cultures of $106 \frac{\mathrm{D}}{\mathrm{D}}$ pairs as identical or non-identical (Table 2).

A few cultures, which appeared similar when $\stackrel{\unrhd}{\varrho}$ typed by a single typing method, were shown to be 
different when their identification profiles were extended. Thus, of the 36 pairs judged to be similar by $\mathrm{O}$ serogrouping, the cultures of the pairs of $\mathbf{0 7 5}$ serotype from patients 5 and 6 were found in each case to be different in biotype, resistotype, and haemagglutinin type (Table 3). Similarly, cultures of identical biotype from patient 7 were readily differentiated by resistotyping and haemagglutinin typing, whereas those of identical resistotype from patient 8 were different in biotype and haemagglutinin type (Table 3).

The only four pairs of cultures for which biotyping and resistotyping results were conflicting and, hence, classed as 'of uncertain status' in Table 2 were those from patients 9 to 12 (Table 3 ). The pair from patient 9 showed three minor differences in resistotype characters that would ordinarily have indicated strain non-identity. ${ }^{1}$ However, apart from one culture having become multiauxotrophic (and which might have influenced the resistotype pattern by its slower growth), the members of that pair were of similar biotype and had the same uncommon haemagglutinin type (Table 3). Similarly, the isolates from patient 10 differed in one major and two minor resistotype characters. However, their biotype profiles, their haemagglutinin types, and their sensitivity to colicins ( $E_{2}$ and $K$ only) were identical (Table 3$)$. On the other hand, the cultures from patient 11 differed in lysine decarboxylase (and lactose) reactions but showed acceptable strain identity, as judged by resistotype, haemagglutinin type, colicin production (col $E_{1}$ ), and colicin sensitivity. The pairs of cultures from patients 9,10 , and 11 were probably in each case isolates of a single strain that had undergone variation of typing character(s) in vivo. The cultures from patient 12 were non-colicinogenic and sensitive to the same colicins (A, B, D, and $E_{2}$ ) but showed difference in two biotyping characters, three minor resistotype characters, and haemagglutinin type (Table 3) so that even extended typing did not resolve the question of their status.

\section{Discussion}

The techniques of biotyping, resistotyping, and haemagglutinin typing had already proved useful for the discrimination of fresh isolates of $E$. coli from urine and diverse other sites. ${ }^{34}$ We wished to investigate their usefulness for the retrospective analysis of strains stored on non-selective medium for many years.

A biotype profile (10 characters) and a resistotype profile (8 characters) were assigned to every culture of the 110 pairs from 110 patients, and, accordingly, the overall typing patterns left little doubt about the relationship between cultures within each pair. The use of only biotyping and resistotyping was sufficient to identify $106(96 \%)$ of the pairs as similar or dissimilar.

There was no correlation between ease or difficulty of identification of isolates and the time interval between their first and last isolations. Thus, for example, five isolates obtained over 227 days from patient 3 were completely stable in all typing characters and were clearly clonal, whereas two cultures from patient 12 isolated 12 days apart proved difficult to define.

Although we examined all cultures in this study by all typing methods it was not generally necessary to use data other than those from biotyping and resistotyping to reach conclusions about strain identity. In those instances $(<5 \%)$ in which we had to extend the typing profiles, we generally favoured haemagglutinin typing but have also used colicin typing, as in this study, and at other times antibiogram testing and limited $\mathrm{O}$ serogrouping. ${ }^{34}$ In the pair of cultures from patient 12, we used all six typing methods but were nevertheless uncertain about their identity. Both cultures were autoagglutinable, antibiotic-sensitive, non-colicinogenic, and sensitive to the same colicins $\left(\mathrm{A}, \mathrm{B}, \mathrm{D}\right.$, and $\left.\mathrm{E}_{2}\right)$ and might have been considered members of the same clone but for the following: of the two observed biotype differences, mutation to auxotrophy is not uncommon, but differences in the ornithine decarboxylase reaction have not previously been encountered by us; $;^{2-4}$ three minor resistotype differences have been noted in isolates otherwise identical (see, for example, patient 9) but resistotype differences are usually recorded in cultures isolated over long time intervals $; 34$ loss of MRE characters has previously been observed. ${ }^{34}$ Thus, if these isolates are clonal in origin, it is unusual that so many variations should have occurred in such a short period. We feel, nevertheless, that the difficulty experienced in this study with a single pair of cultures, the identity of which remains unclear, strengthens rather than weakens our arguments in favour of multiple typing. If it is difficult in such cases to reach a decision about the identity of isolates so extensively studied, how much less satisfactory must be any conclusions drawn from the results of a single typing method.

We have demonstrated in previous publications $\mathrm{s}^{2-4}$ the occasional variation in vivo of some of the characters assessed by biotyping, resistotyping, and haemagglutinin typing, so that each of these techniques used alone would be unsatisfactory for strain identification. However, as long as it is appreciated that variations in the typing characters of isolates of $E$. coli occur in vivo, it should generally be possible to resolve the difficulties of identification by a gradual extension of the typing profile. 
We have no data about the biotype and resistotype profiles of the strains in this series on first isolation because the biotyping and resistotyping techniques that have provided so much useful information in this study were not then available. What evidence is available, therefore, about the stability of these characters in strains of $E$. coli on storage? We have reported elsewhere on both the reproducibility of the systems in multiple tests of fresh isolates of $E$. coli and the stability of the biotype and resistotype characters of some of these isolates retested at random after storage for up to four years. ${ }^{2-4} \mathrm{We}$ suggest that the occasional minor variations in typing characters observed in some isolates otherwise identical, for example, pairs from patients 9,10 , and 11 , are more likely to reflect changes that occurred in the strains in vivo before their deposition rather than changes that occurred in vitro during storage. We are confident, therefore, that our present findings for stored strains reflect accurately their original type profiles.

The multiple typing approach has already proved invaluable for the identification of fresh isolates of $E$. coli. ${ }^{34}$ The results of the present study indicate that it should be equally worth while for the analysis of cultures of $E$. coli stored for many years and suggest that the combined use of just biotyping and resistotyping should generally be sufficient to resolve most questions of strain identity.

\section{References}

${ }^{1}$ Elek SD, Higney L. Resistogram typing - a new epidemiological tool: application to Escherichia coli. J Med Microbiol 1970;3:103-10.

2 Crichton PB, Old DC. Biotyping of Escherichia coli. J Med Microbiol 1979;12:473-86.

${ }^{3}$ Crichton PB, Old DC. Differentiation of strains of Escheri- $\overline{\bar{\omega}}$ chia coli: multiple typing approach. J Clin Microbiol 1980; $11: 635-40$.

${ }^{4}$ Old DC, Crichton PB, Maunder AJ, Wilson MI. Discrimination of urinary strains of Escherichia coli by five typing methods. J Med Microbiol 1980;13:437-44.

${ }^{5}$ Wilson MI. The influence of fimbrial and non-fimbrial $\overrightarrow{ }$ adhesive properties on the infectivity of Escherichia coli. $\omega$ PhD thesis, University of Dundee, 1970.

- Meynell GG, Meynell E. Theory and practice in experimental bacteriology. 1st ed. Cambridge: Cambridge University $\omega$ Press, 1965:56.

${ }^{7}$ Duguid JP, Clegg S, Wilson MI. The fimbrial and nonfimbrial haemagglutinins of Escherichia coli. $J$ Med $\underset{\sim}{\mathbb{A}}$
Microbiol 1979;12:213-27.

${ }^{8}$ Ozeki H, Stocker BAD, Smith SM. Transmission of 윽 colicinogeny between strains of Salmonella typhimurium grown together. J Gen Microbiol 1962;28:671-87.

${ }^{9}$ Barker R, Old DC. Biotyping and colicine typing of Sal- $\frac{7}{O}$ monella typhimurium strains of phage type 141 isolated in Scotland. J Med Microbiol 1979;12:265-76.

Requests for reprints to: Dr DC Old, Bacteriology Department, University of Dundee Medical School, Ninewells Hospital, Dundee DD1 9SY. 